\title{
Identifying Contextual and Emotional Factors to Explore Weight Disparities between Obese Black and White Women
}

\section{Supplementary Issue: Health Disparities in Women}

\author{
NiCole R. Keith ${ }^{1-3}$, Huiping Xu ${ }^{4}$, Mary de Groot ${ }^{5}$, Kimberly Hemmerlein ${ }^{6}$ and Daniel O. Clark ${ }^{1,2,7}$ \\ ${ }^{1}$ Research Scientist, Indiana University Center for Aging Research, 2Investigator, Regenstrief Institute, Inc., ${ }^{3}$ Professor, School of Physical \\ Education and Tourism Management, ${ }^{4}$ Assistant Professor, Division of Biostatistics, Indiana University School of Medicine, ${ }^{5}$ Associate Professor \\ Diabetes Translational Research Center, Indiana University School of Medicine, ${ }^{6}$ Research Coordinator, Indiana University Center for Aging \\ Research, ${ }^{7}$ Associate Professor, Division of General Internal Medicine and Geriatrics, Indiana University School of Medicine, Indianapolis, IN, USA.
}

\begin{abstract}
BACKGROUND: Obese black women enrolled in weight loss interventions experience $50 \%$ less weight reduction than obese white women. This suggests that current weight loss strategies may increase health disparities.

OBJECTIVE: We evaluated the feasibility of identifying daily contextual factors that may influence obesity.

METHODS: In-home interviews with 16 obese (body mass index $\geq 30$ ) black and white urban poor women were performed. For 14 days, ecological momentary assessment (EMA) was used to capture emotion and social interactions every other day, and day reconstruction method surveys were used the following day to reconstruct the context of the prior day's EMA.

RESULTS: Factors included percentage of participants without weight scales (43.8\%) or fitness equipment (68.8\%) in the home and exposed to food at work (55.6\%). The most frequently reported location, activity, and emotion were home (19.4 \pm 8.53$)$, working (7.1 \pm 8.80$)$, and happy (6.9 \pm 10.03$)$, respectively. CONCLUSION: Identifying individual contexts may lead to valuable insights about obesogenic behaviors and new interventions to improve weight management.
\end{abstract}

KEYWORDS: obesity, contextual factors, health disparities

SUPPLEMENT: Health Disparities in Women

CITATION: Keith et al. Identifying Contextual and Emotional Factors to Explore Weight Disparities between Obese Black and White Women. Clinical Medicine Insights: Women's Health 2016:9(S1) 85-93 doi:10.4137/CMWH.S34687.

TYPE: Original Research

RECEIVED: December 21, 2015. RESUBMITTED: July 3, 2016. ACCEPTED FOR PUBLICATION: July 8, 2016

ACADEMIC EDITOR: Nicole Powell-Dunford, Editor in Chief

PEER REVIEW: Four peer reviewers contributed to the peer review report. Reviewers' reports totaled 1859 words, excluding any confidential comments to the academic edito

FUNDING: The project described was supported by Award Number P30 AG024967 from the National Institute on Aging. The content is solely the responsibility of the authors and does not necessarily represent the official views of the National Institute on Aging. The authors confirm that the funder had no influence over the study design content of the article, or selection of this journal.
COMPETING INTERESTS: Authors disclose no potential conflicts of interest.

COPYRIGHT: @ the authors, publisher and licensee Libertas Academica Limited. This is an open-access article distributed under the terms of the Creative Commons CC-BY-NC 3.0 License.

CORRESPONDENCE: nkeith@iupui.edu

Paper subject to independent expert single-blind peer review. All editorial decisions made by independent academic editor. Upon submission manuscript was subject to anti-plagiarism scanning. Prior to publication all authors have given signed confirmation of agreement to article publication and compliance with all applicable ethical and legal requirements, including the accuracy of author and contributor information, disclosure of competing interests and funding sources, compliance with ethical requirements relating to human and animal study participants, and compliance with any copyright requirements of third parties. This journal is a member of the Committee on Publication Ethics (COPE).

Published by Libertas Academica. Learn more about this journal.

\section{Introduction}

The Healthy People 2010 Final Review reported no progress on racial disparities in obesity, and leading obesity scientists have called for more research on the role of physical and social contexts in racial disparities in obesity. ${ }^{1,2}$ The concluding article in an October 2014 Obesity Reviews Special Issue on Achieving Healthy Weight in Black American Communities reported that studies of obesity prevention and treatment in non-Hispanic black adults have been few and of insufficient quality. Black women have high rates of obesity $(>60 \%),{ }^{3}$ and all five leading causes of death among black women are obesity related. ${ }^{4}$ Given this obesity impact, the authors recommended bold research steps in developing and evaluating obesity interventions that address these disparities. ${ }^{5}$

To date, most weight management interventions have provided individuals with information and support in an effort to increase self-control of weight-related behaviors. ${ }^{6}$ Weight loss interventions built on a foundation of deliberate behavior change have generally achieved 50\% less short-term (months) and long-term (years) weight loss in black women compared to non-Hispanic white women. ${ }^{7-10}$ With evidence that every $2 \mathrm{lbs}$ of weight loss is associated with a $10 \%$ reduction in the 3 -year risk of hypertension ${ }^{11}$ and a $16 \%$ reduction in the 3 -year risk of type 2 diabetes, ${ }^{12} 50 \%$ less weight loss translates into substantial lost opportunity for reductions in obesity-related morbidity.

Over the past decade, scientists have become more vocal in the view that much, if not most, of human behavior is automatic in response to cues. ${ }^{13} \mathrm{~A}$ cue is an internal (eg, emotion) or external (eg, others eating) stimulus that triggers "automatic" behavior. ${ }^{14}$ Automatic behaviors are initiated without intention, continue with little effort, and occur with limited awareness. ${ }^{15}$ In fact, experimental research has demonstrated a powerful influence of cues on eating behavior, ${ }^{16}$ and our previous research suggests that food cues are pervasive in the lives and homes of obese urban poor women. ${ }^{17}$ Lifestyle 
interventions often do provide participants with information about cues and how to "take charge of what's around you", ${ }^{18}$ but the field of automaticity has shown that humans are largely unaware of cues and their influence on desires and behaviors. ${ }^{15,19}$ Establishing novel methods to identify, evaluate, and quantify the contexts to which obese black compared to obese white women are exposed may lead to valuable insight into the cues that trigger obesogenic behaviors. This may lead to new interventions to improve weight management.

Urban poor black and white women are often exposed to similar community contexts or macroenvironmental cues (unhealthy advertising, fast food restaurants, or convenience stores). ${ }^{1}$ However, external microenvironment (eg, social interactions) and internal factors (eg, emotions) may be quite different. ${ }^{1,2,20,21}$ For example, urban poor black women often report being part of social networks that support obesity and intake of foods that are high in fat, sodium, and sugar. ${ }^{17,22}$ Urban poor white women, on the other hand, report social networks that support and encourage small body sizes. ${ }^{17,22}$ While it is well known that internal and external factors affect weight-related behavior, ${ }^{23}$ to our knowledge, these factors have not been extensively studied in the urban poor women. The Institute of Medicine (IOM) has identified obesity research in the urban poor women as a particularly high priority. ${ }^{24}$

Investigating the role of contexts and designing interventions to address these potential cues require an approach to capturing the microenvironment context (ie, time, place, and social and physical circumstances and activities) and emotions as they occur in daily life. The purpose of this report is to describe an approach to identifying these factors as they occur in the daily lives of urban poor obese black and obese white women. We developed and tested the feasibility of delivering ecological momentary assessments (EMAs) via short message service, "text", paired with the day reconstruction method (DRM) obtained over the telephone to identify time-varying context and emotion. To our knowledge, this is the first study to apply this approach to the study of microenvironmental contexts or emotions of obese urban poor adults.

\section{Methods}

Given the complexity of capturing context and time-varying factors, we used multiple methodologies. Both EMA and DRM are designed to improve recall bias over traditional survey methods. ${ }^{25}$ EMA is an assessment method in which repeated measures (in this case, multiple times per day) of variables are obtained in real time from individuals in their natural environment. ${ }^{26}$ EMA has been identified as the gold standard for the assessment of everyday life. ${ }^{25} \mathrm{~A}$ recent investigation showed that EMA is more valid for highly time-varying factors such as emotion than DRM but that DRM is of equal validity for moderately time-varying factors such as location. ${ }^{27}$ Our preliminary feasibility testing showed, with the same incentive structure as this study (described later), that urban poor adults responded poorly to EMA requests that required more than 30 seconds to complete multiple times per day. In response, we developed a hybrid EMA-DRM method. We used EMA to capture emotion and social interactions on every other day sequence and drew upon DRM telephone surveys the following day to reconstruct the context of the prior day's EMA-reported emotion and social interactions. In addition, prior to initiating the EMA and DRM data collection, we completed survey measures that included an in-home assessment using a structured interview and observations of the home environment. The in-home assessment provided data to characterize the samples and to improve the efficiency of EMA reporting. We review the approach and measures for the in-home assessment, EMA, and DRM separately later.

Participant recruitment and eligibility. Obese black and white women were recruited from federally qualified health centers (FQHC). Health system data managers with access to electronic medical records (EMRs) reviewed patient records to identify those who met the study demographic criteria. Permission to contact potential participants was sought from each potential participant's FQHC provider by two practice-based research network (PBRN) research assistants (RAs). Potentially eligible participants received a telephone call from a PBRN RA inviting the patient to participate in the study. Those who indicated interest completed a brief screen. Participants included in this research were aged 35-64 years, female, seen by a provider at one or more FQHC within the past 12 months, obese (body mass index $[\mathrm{BMI}] \geq 30$ ), spoke English as a primary language, self-identified as non-Hispanic black or white, and had a permanent address. Women were excluded from the study if they had a history of bipolar disorder or psychosis or schizophrenia, mental health treatment including for eating disorders and drug/alcohol abuse, severe cognitive impairment (three or more errors on a six-item cognitive screen), were unwilling or unable to provide informed consent, were receiving disability insurance, had bariatric surgery already completed or planned within 12 months, current cancer or diabetes (Type 1 or 2) diagnosis, lived outside of Marion County, Indiana, were substance abusers (for alcohol; $\geq 2$ on Cage questionnaire), smoked, or were pregnant. Eligible participants received a follow-up phone call from a study staff member to schedule an appointment for informed consent and baseline assessment. This study was approved by the Indiana University Institutional Review Board. The research was conducted in accordance with the principles of the Declaration of Helsinki.

Procedures. RAs and study participants were race and gender matched; one black female RA assessed the black female participants, and one white female RA assessed the white female participants. In our previous research, we found that the most successful assessments occurred when the interviewers and participants were of the same race and gender. ${ }^{17}$ The RAs were trained as a team by the same research coordinator to conduct physical measures, participant interviews, and in-home observations of potential obesogenic cues that were 
determined by the consensus of the study team (eg, food types or amounts visible, food storage method or location, presence or absence of exercise equipment, number of screens visible, etc.).

Age and disease diagnoses were obtained from EMRs. Survey measures described in the "Survey measures" section included household income, employment hours, years of education, health literacy, numeracy, food security, depression, anxiety, and social network characteristics. All survey measures were interviewer-administered.

Immediately following completion of the surveys, while still in the home, the RAs measured and recorded the participant's height, weight, and waist circumference. Next, the RA handed the participant a smart phone or a card to attach to the back of the participant's smart phone. The card contained response codes to make it easy and quick for participants to respond to the EMA. ${ }^{26}$

Participants were reminded (as stated in the informed consent) that over the next 14 days, six to eight times per day between the hours of 9AM and 9PM, they would receive EMA text messages approximately every other day (meaning one day was skipped between each day of EMA data collection). We asked participants to respond to the EMA as soon as it was safe and they were able (within the hour). They were also reminded they would receive a phone call from a study RA every other day (on days when the EMAs were not completed) to complete a DRM survey. ${ }^{28}$ Participants identified the best time of day to be contacted to complete the DRM.

After exiting the home, the RA completed a checklist of questions regarding obesogenic factors in the home. For example, RAs reported whether a frying pan was visible on the stove and whether other plates, dishes, or cups were visible.

EMA-DRM. We conducted EMA surveys of both social and individual interactions and mood. Participants were asked how they were feeling, with whom they were interacting, and what they were doing. Participants selected up to 13 adjectives to convey how they were feeling at the moment. For social interaction, participants reported as many as applied from a provided list of close ties or other social contacts. Close ties were people participants had named as such on the inhome survey ("Survey Measures" section). There were 17 possible activity selections. Using the provided codes, EMA survey responses required less than 15 seconds to complete.

We used EMA and DRM as complementary assessment methods. The DRM survey was completed by telephone on the day immediately following an EMA day. The DRM survey asked participants to respond to questions about location, activities, and surroundings at each EMA episode. DRM questions were adapted from those developed and validated by Cohen and Lemay ${ }^{29}$ and Kamarck et al. ${ }^{30,31}$ Coupled with the information obtained from the EMA, each DRM took less than 10 minutes to complete.

Participants received a $\$ 50$ gift card for the in-home assessment, \$0.25 for each completed EMA text message, and $\$ 1.00$ for each completed DRM phone call.
In-home survey measures. We used multiple measures to assess health literacy and numeracy as these are particularly critical to the study of obesity in the urban poor women. A score of 6 or less on the Rapid Estimate of Adult Literacy in Medicine, Revised (REALM-R), indicates low health literacy and a score greater than 6 indicates acceptable health literacy. ${ }^{32}$ We also used the New Vital Sign (NVS) instrument to determine both health literacy and numeracy. ${ }^{33}$ Participants with more than four correct answers are likely to have acceptable health literacy and numeracy. The 8-item Subjective Numeracy Scale (SNS) was also used. The SNS was designed to provide a brief way of determining math ability without producing respondent anxiety. ${ }^{34-36}$

We used the United States Department of Agriculture US Household Food Security Module: Six-Item Short Form to assess food security. ${ }^{37}$ Scores of $0-1$ indicate high or marginal food security, 2-4 indicate low food security, and 5-6 indicate very low food security.

Emotional state was measured using the Patient Health Questionnaire 8-item depression scale (PHQ-8) and the 7-item Generalized Anxiety Disorder (GAD 7) scale. A PHQ-8 score of 10 or more is indicative of current depression. ${ }^{38,39}$ Higher scores are strongly associated with multiple domains of functional impairment (all six Medical Outcomes Study ShortForm General Health Survey scales and disability days). ${ }^{40}$

Social networks included people participants felt close to and trusted. For each person, they indicated whether they lived with the person, regularly ate with the person, and/or exercised with the person. The participant also indicated whether the person was involved in weight self-management. The participant was asked to describe her relationship with the person (eg, sister) as well as the person's race. The participant was shown a body figure rating scale ${ }^{41}$ to identify the figure most similar to the person's body size. Trusted close ties was determined from the sum of affirmative responses to three questions; would you ask this person for help if sick, for a loan, and/or to babysit. ${ }^{42}$

From the measures captured in the in-home survey, observational, EMA, and DRM, we created variables representing context, activity, and emotion. We categorized these as either fixed (eg, number of televisions) or time-varying (eg, social interactions) factors. EMA and DRM data were regarded primarily as time varying. Social interactions, activities, and locations reported in EMA and DRM were combined to create time-varying social and individual activities (eg, eating alone, eating with others). We identified relatively fixed contextual factors from the participant's responses to the RA-administered in-home survey and the RA's assessments of the home.

Analyses. Baseline sample characteristics were examined with continuous variables presented using mean and standard deviations and categorical variables summarized using absolute and relative frequencies. Fixed contextual factors were 
reported similarly. Time-varying information based on the EMA and DRM were summarized on the subject level using the total number of EMAs for which specific types of social interaction, activity, location, or emotion were reported. Mean and standard deviation were then computed for the total sample and for black and white women separately.

\section{Results}

Recruitment and study sample characteristics. From electronic lists of FQHC patients, 20 of 84 (23.8\%) obese women contacted by telephone initially agreed to participate in this research. On a subsequent telephone call to schedule consent and assessments, we were unable to reach three of the 20 participants (phone disconnected and failure to answer phone/respond to voice messages after five attempts). We consented 17 participants and one was automatically withdrawn for failure to complete two consecutive DRMs as per our study protocol. Twelve of the remaining 16 participants elected to use their own smartphone, four used a study smartphone, and all completed this research with no technical difficulties.

Descriptive data of the total sample and each race group are presented in Table 1. Participant mean age was $56.6 \pm 7.8$ years. The mean BMI was $38.9 \pm 5.4$, mean waist circumference was $45.8 \pm 5.3$, and mean hip circumference was $49.8 \pm 3.6$. The mean food security score was $1.9 \pm 2.2$, indicating marginal to low food security in our sample. Participants had an average of $12.0 \pm 1.54$ years of education, an average household annual income of $\$ 18,000 \pm \$ 15,000$, and $2.4 \pm 1.4$ people were living in the household and spent on average of $29.4 \pm 10.8$ hours at work. Eighteen percent of the women reported having fair or poor health, $12.5 \%$ were depressed (PHQ $\geq 10$ ), and $6.3 \%$ reported being anxious $(\mathrm{GAD} \geq 10$ ). The women had low numeracy, as indicated by the average SNS score of $3.2 \pm 1.1$, and demonstrated inadequate health literacy $2.9 \pm 2.1$ (NVS) and $4.6 \pm 2.9$ (REALM-R).

EMA and DRM completion. Each participant received a total of 40 EMA text messages on six days of the 14-day study. The DRM survey was conducted on the day after each EMA day, resulting in six attempted DRM surveys for each respondent. Of the total of 40 EMA prompts, $74.3 \%$ were completed for both groups. Based on both the EMAs and DRMs, the location of the women at the time of the EMA prompts was reported for an average of 35.8 out of 40 times with a standard deviation of 6.3 times. Activity was reported $35.3 \pm 7.7$ times. Ninety percent (mean $5.4 \pm 1.0$ ) of six attempted DRM surveys were completed for both groups. From these data, we identified variables that represented time-varying context, emotions, and activities.

In-home observations. Processed, high-fat, low-nutrient foods with excess clutter around the home including boxed food and canned goods (some piled up to $4 \mathrm{ft}$ high) in the homes of the white women. Additionally, food was seen in several rooms throughout the homes of the white women.

Table 1. Sample characteristics at baseline assessment.

\begin{tabular}{|c|c|c|c|}
\hline VARIABLES & $\begin{array}{l}\text { TOTAL } \\
(\mathrm{N}=16)\end{array}$ & $\begin{array}{l}\text { OBESE BLACK WOMEN } \\
(\mathrm{N}=10)\end{array}$ & $\begin{array}{l}\text { OBESE WHITE WOMEN } \\
(\mathrm{N}=6)\end{array}$ \\
\hline Age, mean (SD) & $56.6(7.8)$ & $57.4(8.4)$ & $55.3(7.3)$ \\
\hline BMI, mean (SD) & $38.9(5.4)$ & $38.4(3.6)$ & $39.6(7.9)$ \\
\hline Waist circumference, mean (SD) & $45.8(5.3)$ & $44.8(4.2)$ & $47.5(7.0)$ \\
\hline Hip circumference, mean (SD) & $49.8(3.6)$ & $49.4(3.5)$ & $50.3(4.1)$ \\
\hline Years of education, mean (SD) & $12(1.6)$ & $12.5(1.6)$ & $11.2(1.3)$ \\
\hline Household income, mean (SD) & $\$ 18 k(15 k)$ & $\$ 19 k(17 k)$ & $\$ 15 k(12 k)$ \\
\hline Number of people in household, mean (SD) & $2.4(1.4)$ & $1.8(1.3)$ & $3.3(1.0)$ \\
\hline Hours at work per week, mean (SD) & $29(10.8)$ & $31(8.9)$ & $27(13.0)$ \\
\hline History of smoking, $\mathrm{n}(\%)$ & $6(37.5 \%)$ & $4(40.0 \%)$ & $2(33.3 \%)$ \\
\hline Fair or poor perceived health, $\mathrm{n}(\%)$ & $3(18.8 \%)$ & $1(10.0 \%)$ & $2(33.3 \%)$ \\
\hline Patient Health Questionnaire, mean (SD) & $5.3(5.7)$ & $4.5(4.4)$ & $6.7(7.8)$ \\
\hline Percent depressed (PHQ $\geq 10), n(\%)$ & $2(12.5 \%)$ & $1(10.0 \%)$ & $1(16.7 \%)$ \\
\hline Generalized Anxiety, mean (SD) & $3.6(5.2)$ & $2.4(2.6)$ & $5.7(5.6)$ \\
\hline Percent anxious (GAD $\geq 10), \mathrm{n}(\%)$ & $1(6.3 \%)$ & $0(0.0 \%)$ & $1(16.7 \%)$ \\
\hline Subjective numeracy scale, mean (SD) & $3.2(1.1)$ & $3.5(1.0)$ & $2.7(1.1)$ \\
\hline Newest Vital Sign (NVS) for health literacy, mean (SD) & $2.9(2.1)$ & $3.2(2.1)$ & $2.3(2.3)$ \\
\hline $\begin{array}{l}\text { Rapid estimate of adult literacy in medicine, revised } \\
\text { (REALM-R), mean (SD) }\end{array}$ & $4.6(2.9)$ & $4.7(2.9)$ & $4.5(3.3)$ \\
\hline $\begin{array}{l}\text { Food security survey (5-6 very low food security), } \\
\text { mean (SD) }\end{array}$ & $1.9(2.2)$ & $1.9(2.3)$ & $1.8(2.1)$ \\
\hline
\end{tabular}


Fresh fruits and vegetables, condiments, and food preparation items (eg, butter, spices, margarine, vegetable oil, etc.) as well as saved bacon/meat fat were observed in the homes of black women. No food was observed outside of the kitchens of the black women's homes.

Fixed contextual factors. Table 2 shows fixed contextual factors including the average number of televisions in the home $(n=3.1 \pm 1.3)$ and social network ties $(n=3.3 \pm 1.1)$. The mean number of trusted ties was three for both groups, but very few of these ties were regarded as obese although many ties were reported to be inactive, food unaware, and weight unaware. In addition to these factors, we report in Table 2 the percentage of participants without weight scales in the home (43.8\%), without fitness equipment in the home (68.8\%), and who are exposed to food on the job (55.6\%).

\section{Time-varying contextual factors.}

Location. Women reported being in their own homes during more than half of the responses (19.4 \pm 8.5 times). The next two most often (albeit less frequently) reported locations were at work $(5.1 \pm 6.9$ times $)$ and at the home of a social contact/network tie $(3.1 \pm 6.6$ times $)$. The latter location was more frequent among black women than white women. Other locations, which included retail, community, vehicle, and entertainment, are also presented by race category and for the entire group in Table 3.

Activities. On average, the women most frequently reported that they were working $(7.1 \pm 8.8$ times $)$, watching television (6.5 \pm 5.6 times), napping/resting ( $4.9 \pm 5.3$ times), eating ( $4.8 \pm 3.2$ times), and/or relaxing ( $4.4 \pm 4.0$ times). Other activities also presented in Table 3 include computer/ Internet/email, doing housework, commuting, shopping, preparing food, taking care of children, exercising, interacting, and performing various activities with obese ties (specified in Table 3). Participants could report doing more than one activity as they were not mutually exclusive.
Emotion. Participants reported having very little emotional variability and most frequently reported being happy (16.9 \pm 10.0 times), tired (6.9 \pm 5.9 times), and warm/friendly (4.7 \pm 4.6 times). Other emotions presented in Table 3 included feeling frustrated/annoyed, depressed/blue, entertained, competent/capable, hassled/pushed around, angry/ hostile, worried/anxious, enjoyed yourself, criticized/put down, and bored. Additional time-varying factors describing the social network ties of all participants and for each separate race group are also presented in Table 3.

Food exposure. Another time-varying factor identified by the DRM survey was the number of times food could be viewed or smelled throughout the day. On average, black women reported being able to see or smell food $16.8 \pm 7.1$ times and white women reported being able to see or smell food $14.3 \pm 10.5$ times. This meant both groups could see or smell food just over half of the times they were asked. These data are presented in Table 3.

Social interaction. The final time-varying factors we identified using the DRM surveys were whether participants were interacting with others, and if so whether food, physical activity, or weight were discussed. If these topics were discussed, participants were asked whether they felt supported in those discussions. Both groups frequently reported interacting with others $(23.1 \pm 8.3)$. Food was discussed most often $(8.1 \pm 6.4)$, and both groups generally felt supported in the conversation (7.8 \pm 6.6$)$. Physical activity and weight were discussed less often (Table 3 ).

\section{Conclusion}

We have shown that with careful attention to participant burden, it is feasible to collect novel data regarding context and emotion among very poor, low-health literacy black and white women. The limited number of studies that have measured social mechanisms of weight change among black women

Table 2. Research assistant's record of fixed contextual factors.

\begin{tabular}{|c|c|c|c|}
\hline VARIABLES & $\begin{array}{l}\text { TOTAL } \\
(\mathrm{N}=16)\end{array}$ & $\begin{array}{l}\text { OBESE BLACK WOMEN } \\
(\mathrm{N}=10)\end{array}$ & $\begin{array}{l}\text { OBESE WHITE WOMEN } \\
(\mathrm{N}=6)\end{array}$ \\
\hline Number of TVs, mean (SD) & $3.1(1.34)$ & $2.7(1.34)$ & $3.7(1.21)$ \\
\hline TV in bedroom, $\mathrm{n}(\%)$ & $15(93.8 \%)$ & $9(90.0 \%)$ & $6(100 \%)$ \\
\hline TV in kitchen, $\mathrm{n}(\%)$ & $2(12.5 \%)$ & $2(20.0 \%)$ & $0(0.0 \%)$ \\
\hline No weight scales in home, $\mathrm{n}(\%)$ & $7(43.8 \%)$ & $5(50.0 \%)$ & $2(33.3 \%)$ \\
\hline No fitness equipment in home, $\mathrm{n}(\%)$ & $11(68.8 \%)$ & $7(70.0 \%)$ & $4(66.7 \%)$ \\
\hline Food on job among those who work, $\mathrm{n}(\%)$ & $5(31.3 \%)$ & $3(30.0 \%)$ & $2(33.3 \%)$ \\
\hline Number of social network ties, mean (SD) & $3.3(1.1)$ & $3.2(1.1)$ & $3.5(1.2)$ \\
\hline Number of trusted ties, mean (SD) & $3.1(1.2)$ & $3(1.3)$ & $3.3(1.2)$ \\
\hline Number of obese ties, mean (SD) & $0.6(0.9)$ & $0.3(0.5)$ & $1(1.3)$ \\
\hline Number of inactive ties, mean (SD) & $1.9(1.3)$ & $1.8(1.3)$ & $2(1.3)$ \\
\hline Number of weight unaware ties, mean (SD) & $1.9(1.4)$ & $1.9(1.4)$ & $1.8(1.5)$ \\
\hline Number of food unaware ties, mean (SD) & $2.1(1.0)$ & $2.1(1.0)$ & $2.2(1.2)$ \\
\hline
\end{tabular}


Table 3. Time-varying contextual factors.

\begin{tabular}{|c|c|c|c|}
\hline VARIABLES & $\begin{array}{l}\text { TOTAL } \\
(\mathrm{N}=16)\end{array}$ & $\begin{array}{l}\text { OBESE BLACK WOMEN } \\
(\mathrm{N}=10)\end{array}$ & $\begin{array}{l}\text { OBESE WHITE WOMEN } \\
(\mathrm{N}=6)\end{array}$ \\
\hline \multicolumn{4}{|l|}{ Location when receiving EMA, mean (SD) } \\
\hline Total number of times location was reported & $35.8(6.3)$ & $35.3(7.7)$ & $36.5(3.1)$ \\
\hline \multicolumn{4}{|l|}{ Number of times specific location was reported } \\
\hline Own home & $19.4(8.5)$ & $18.9(6.2)$ & $20.3(12.2)$ \\
\hline Work & $5.1(6.9)$ & $4.2(5.1)$ & $6.5(9.5)$ \\
\hline Network home & $3.1(6.6)$ & $4.1(8.1)$ & $1.5(2.5)$ \\
\hline Retail & $1(1.0)$ & $1.2(1.0)$ & $0.8(1.0)$ \\
\hline Community & $2.2(2.3)$ & $2.4(2.4)$ & $1.8(2.4)$ \\
\hline Vehicle & $1.8(1.7)$ & $1.6(1.3)$ & $2(1.3)$ \\
\hline Entertainment & $1.6(1.6)$ & $1.8(1.9)$ & $1.3(1.0)$ \\
\hline \multicolumn{4}{|l|}{ Activity when receiving EMA, mean (SD) } \\
\hline Total number of times activity was reported & $35.3(7.7)$ & $36.5(3.1)$ & $35.3(7.7)$ \\
\hline \multicolumn{4}{|l|}{ Number of times specific activity was reported } \\
\hline Watching TV & $6.5(5.6)$ & $7.8(6.1)$ & $4.3(4.2)$ \\
\hline Computer/Internet/email & $1.2(2.0)$ & $1.1(2.2)$ & $1.3(1.8)$ \\
\hline Napping/resting & $4.9(5.3)$ & $3.6(2.0)$ & $7.2(8.2)$ \\
\hline Relaxing & $4.4(4.0)$ & $4.3(3.1)$ & $4.7(5.5)$ \\
\hline Working & $7.1(8.8)$ & $5.1(4.7)$ & $10.3(13.1)$ \\
\hline Doing housework & $1.4(1.4)$ & $1.4(1.1)$ & $1.3(2.0)$ \\
\hline Commuting & $1.8(1.6)$ & $1.5(1.4)$ & $2.3(2.0)$ \\
\hline Shopping & $1.5(1.3)$ & $1.6(1.2)$ & $1.3(1.5)$ \\
\hline Preparing food & $1.3(1.5)$ & $1.5(1.4)$ & $1(1.6)$ \\
\hline Taking care of children & $0.1(0.5)$ & $0.2(0.6)$ & 0 \\
\hline Exercising & $0.1(0.3)$ & $0.1(0.3)$ & 0 \\
\hline Socializing, on the phone, and intimate relations & $3.1(3.1)$ & $2.8(2.3)$ & $(4.3)$ \\
\hline Socializing, on the phone, and intimate relations with obese ties & $0.1(0.3)$ & $0.1(0.3)$ & $0.2(0.4)$ \\
\hline Socializing with obese ties & $0.1(0.3)$ & 0.0 & $0.2(0.4)$ \\
\hline On the phone with obese ties & $0.1(0.25)$ & $0.1(0.32)$ & 0.0 \\
\hline Intimate relation with obese ties & 0.0 & 0.0 & 0.0 \\
\hline Eating & $4.8(3.2)$ & $4.6(3.2)$ & $5(3.4)$ \\
\hline Eating alone & $0.8(0.9)$ & $0.9(0.9)$ & $0.7(1.0)$ \\
\hline Eating with others & $3.9(2.9)$ & $3.7(3.0)$ & $4.3(2.9)$ \\
\hline Eating with obese ties & $0.6(2.3)$ & $0.9(2.9)$ & $0.2(0.4)$ \\
\hline \multicolumn{4}{|l|}{ Emotions when receiving EMA, mean (SD) } \\
\hline Total number of times emotion was reported & $37.2(5.7)$ & $36.4(7.2)$ & $38.5(1.4)$ \\
\hline \multicolumn{4}{|l|}{ Number of times specific emotion was reported } \\
\hline Happy & $16.9(10.0)$ & $13.3(7.7)$ & $23(11.2)$ \\
\hline Frustrated/annoyed & $1.4(2.7)$ & $1.4(2.5)$ & $1.5(3.2)$ \\
\hline Depressed/blue & $0.4(0.7)$ & $0.1(0.3)$ & $1(0.9)$ \\
\hline Entertained & $1.3(1.9)$ & $1.6(2.1)$ & $0.8(1.6)$ \\
\hline Competent/capable & $1.4(2.9)$ & $2.2(3.5)$ & 0.0 \\
\hline Hassled/pushed around & $0.3(0.6)$ & $0.5(0.71)$ & 0.0 \\
\hline Warm/friendly & $4.7(4.6)$ & $6(5.2)$ & $2.5(2.2)$ \\
\hline Angry/hostile & 0.0 & 0.0 & 0.0 \\
\hline Worried/anxious & $0.6(1.3)$ & $0.9(1.5)$ & 0.0 \\
\hline Enjoyed yourself & $2.8(4.1)$ & $4(4.8)$ & $0.8(1.2)$ \\
\hline
\end{tabular}


Table 3. (Continued)

\begin{tabular}{|c|c|c|c|}
\hline VARIABLES & $\begin{array}{l}\text { TOTAL } \\
(\mathrm{N}=16)\end{array}$ & $\begin{array}{l}\text { OBESE BLACK WOMEN } \\
(\mathrm{N}=10)\end{array}$ & $\begin{array}{l}\text { OBESE WHITE WOMEN } \\
(\mathrm{N}=6)\end{array}$ \\
\hline Criticized/put down & 0.0 & 0.0 & 0.0 \\
\hline Tired & $6.9(5.9)$ & $5.5(2.9)$ & $8.7(9.1)$ \\
\hline Bored & $0.6(1.1)$ & $0.9(1.3)$ & $0.2(0.4)$ \\
\hline \multicolumn{4}{|l|}{ Other information when receiving EMA, mean (SD) } \\
\hline Number of times when food can be seen or smelled & $15.9(8.3)$ & $16.8(7.1)$ & $14.3(10.5)$ \\
\hline \multicolumn{4}{|l|}{ Number of times interacting with others } \\
\hline Total number of times interacting with others & $23.1(8.3)$ & $22.2(8.2)$ & $24.7(9.1)$ \\
\hline Discussing food while interacting with others & $8.1(6.4)$ & $7.5(4.8)$ & $9(8.9)$ \\
\hline Felt supported in the conversation about food & $7.8(6.6)$ & $7.2(5.26)$ & $8.8(8.9)$ \\
\hline Discussing physical activity while interacting with others & $2.8(3.9)$ & $3.3(4.6)$ & $1.8(2.8)$ \\
\hline Felt supported in the conversation about physical activity & $2.8(3.9)$ & $3.3(4.6)$ & $1.8(2.8)$ \\
\hline Discussing weight while interacting with others & $1.7(2.6)$ & $2.1(2.9)$ & $1(2.0)$ \\
\hline Felt supported in the conversation about weight & $1.7(2.6)$ & $2.1(2.9)$ & $1(2.0)$ \\
\hline
\end{tabular}

have concluded that black women have less support for weight loss. ${ }^{1,2}$ A 2013 review of weight loss interventions in black women identified preferences for larger body size and lower social support for weight loss behaviors as high priority for future research on weight loss in black women. ${ }^{43}$ Research has previously shown that black women are exposed to social networks with more prevalent obesity and to more calorically dense foods. ${ }^{1,21,43-48}$ One important finding of this study is that urban poor women, whether black or white, frequently reported interacting with others and that food was discussed more often than physical activity and weight. Future work that captures measures of context and emotion along with measures of obesogenic behaviors like eating and sedentariness may allow for the identification of obesogenic cues.

The most frequent activities reported were working, watching television, napping/resting, relaxing, and eating. These are primarily sedentary activities, and sedentary activities have previously been shown to be associated with obesity. The Nurses' Health Study, for example, followed a cohort of 50,277 women from 11 US states and identified an association between sedentary behavior and obesity. Each two hours per day spent television viewing resulted in a $23 \%$ (95\% confidence interval [CI], $17 \%-30 \%)$ increase in obesity risk. Results also indicated that each two hours per day spent sitting at work was associated with a $5 \%(95 \% \mathrm{CI}, 0 \%-10 \%)$ increase in obesity risk. Identifying these behaviors in real time while also identifying the context of the behavior may allow for opportunities to intervene upon or disrupt obesogenic behaviors at the time and context in which they most often occur.

This was a small feasibility study, and generalizations or statistical comparisons are not possible from the data. However, in this small sample, there were no large differences between black and white women as both groups reported similar food exposures, emotions, and activities. Our small sample size does not permit us to evaluate statistical differences between race groups. Rather, we present trends that suggest that further need for investigation of the differences among contextual factors between the two race groups may be warranted. We also acknowledge that offering monetary incentives to participate in the study could present undue influence. However, the incentives, recruitment rate, and retention rate for this study were similar to what we have experienced in other research involving this population. One caution is that socioeconomic status is a strong correlate of nutrition and obesity. ${ }^{2}$ Our focus was on the urban poor women, a subpopulation singled out as high priority for obesity research by the IOM. ${ }^{24} \mathrm{~A}$ focus on the urban poor women of a single city and a single health system largely controls the effects of socioeconomic status and health care access on disparities that may eliminate a majority of race differences in the context of weight behavior. We are presenting this project as a way to capture the type and prevalence of obesogenic factors among black and white adults more generally.

Reports have called for new approaches to the study of obesity, particularly in the urban poor and minority women. ${ }^{5}$ This report reviews the first step in what is a new approach. To our knowledge, our research is the first attempt to operationalize and assess microenvironment contexts and emotions in real time with a focus on racial disparities in obesity or weight loss. Our research demonstrated that obese women were willing and able to respond to EMA text messages and DRM phone calls and identify their locations, interactions, emotions, and activities. Within just 15 seconds, and in the context of their microenvironments, participants can report real-time (and likely very accurate) responses to reveal potential obesogenic contextual factors related to both internal and/or external stimuli (time, place, emotion, and social and physical circumstances) that frequently accompany energy 
intake or sedentary behavior. We have also developed and successfully piloted a novel method of collecting data where the participant's microenvironment can be assessed for fixed potential cues via RA in-home observations. This revealed a large number of televisions in the home and food that was out and visible as well as pervasive food cues (eg, smells).

Future steps in this work will involve the inclusions of continuous measures of weight-related behavior (eg, accelerometers), sample sizes sufficient for comparisons, and, possibly, the inclusion of nonpoor or nonobese groups for greater contrasts of context and emotions. The inclusion of near-continuous behavior measures would allow time-dependent tests of momentary cue exposure and obesogenic behavior. Achieving each of the future steps could identify obesogenic cues in the lives of obese black and obese white women and which of these cues account for similarities or differences in obesity and weight loss. This could provide a guide to novel interventions that address disparities in obesity and weight loss.

\section{Acknowledgments}

We thank Kisha Alexander, Anietra Butler, and Marla Mock for their assistance with data collection and management for this project. This research was the subject of a poster presentation at the American College of Sports Medicine annual meeting in 2016.

\section{Author Contributions}

Conceived and designed the experiments: NRK, DOC, KH. Analyzed the data: HX, MdG. Wrote the first draft of the manuscript: NRK, DOC. Contributed to the writing of the manuscript: $\mathrm{MdG}, \mathrm{KH}$. Agree with manuscript results and conclusions: NRK, DOC, KH, HX, MdG. Jointly developed the structure and arguments for the paper: NRK, DOC. Made critical revisions and approved final version: HX, MdG. All authors reviewed and approved the final manuscript.

\section{REFERENCES}

1. Ard JD, Greene LE, Malpede CZ, Jefferson WK. Association between body image disparity and culturally specific factors that affect weight in Black and White women. Ethn Dis. 2007;17(2 suppl 2):S2-S34.

2. Kumanyika SK, Whitt-Glover MC, Gary TL, et al. Expanding the obesity research paradigm to reach African American communities. Prev Chronic Dis. 2007;4(4):A112.

3. Ogden C, Carroll M, Kit B, Flegal K. Prevalence of Obesity among Adults: United States, 2011-2012. NCHS Data Brief No. 131. Hyattsville, MD: National Center for Health Statistics; 2013:2013.

4. Voelker R. Reducing Preventable Deaths. Chicago, IL: American Medical Association; 2014.

5. Kumanyika S, Whitt-Glover M, Haire-Joshu D. What works for obesity prevention and treatment in black Americans? Research directions. Obes Rev. 2014; 15(S4):204-212.

6. Gorin AA, Raynor HA, Fava J, et al. Randomized controlled trial of a comprehensive home environment-focused weight-loss program for adults. Health Psychol. 2013;32(2):128-137.

7. Tussing-Humphreys L, Pustacioglu C, Nemeth E, Braunschweig C. Rethinking iron regulation and assessment in iron deficiency, anemia of chronic disease, and obesity: introducing hepcidin. J Acad Nutr Diet. 2012;112(3):391-400.

8. Wadden TA, West DS, Neiberg RH, et al. One-year weight losses in the look AHEAD study: factors associated with success. Obesity. 2009;17(4):713-722.

9. West DS, DiLillo V, Bursac Z, Gore SA, Greene PG. Motivational interviewing improves weight loss in women with type 2 diabetes. Diabetes Care. 2007;30(5): 1081-1087.
10. Wingo B, Carson T, Ard J. Differences in weight loss and health outcomes among African Americans and whites in multicentre trials. Obes Rev. 2014;15(S4):46-61.

11. Stevens VJ, Obarzanek E, Cook NR, et al. Long-term weight loss and changes in blood pressure: results of the trials of hypertension prevention, phase II. Ann Intern Med. 2001;134(1):1-11.

12. Hamman RF, Wing RR, Edelstein SL, et al. Effect of weight loss with lifestyle intervention on risk of diabetes. Diabetes Care. 2006;29(9):2102-2107.

13. Marteau TM, Ashcroft RE, Oliver A. Using financial incentives to achieve healthy behaviour. BMJ. 2009;338:b1415.

14. Duhigg C. The Power of Habit: Why We Do What We Do and How to Change. New York: Random House; 2013.

15. Kahneman D, Tversky A. Choices, Values, and Frames. New York: Cambridge University Press; 2000.

16. Wansink B. Mindless Eating: Why We Eat More Than We Think. New York: Random House LLC; 2007.

17. Keith NR, Hemmerlein KA, Clark DO. Weight loss attitudes and social forces in urban poor black and white women. Am J Health Behav. 2015;39(1):34-42.

18. Ackermann RT, Marrero DG. Adapting the diabetes prevention program lifestyle intervention for delivery in the community the YMCA model. Diabetes Educ. 2007;33(1):69-78.

19. Bargh JA, Chartrand TL. The unbearable automaticity of being. Am Psychol. 1999;54(7):462.

20. Barnes AS, Kimbro RT. Descriptive study of educated African American women successful at weight-loss maintenance through lifestyle changes. J Gen Intern Med. 2012;27(10):1272-1279.

21. James DC. Weight loss strategies used by African American women: possible implications for tailored messages. J Hum Nutr Diet. 2013;26(1):71-77.

22. Malpede CZ, Greene LF, Fitzpatrick SL, et al. Racial influences associated with weight-related beliefs in African American and Caucasian women. Race Ethn Health. 2012:291-302.

23. Kumanyika S. Obesity, health disparities, and prevention paradigms: hard questions and hard choices. Prev Chronic Dis. 2005;2(4):A02.

24. Institute of Medicine. Comparative Effectiveness Research. Washington, DC: Institute of Medicine; 2009.

25. Kahneman D, Krueger AB, Schkade DA, Schwarz N, Stone AA. A survey method for characterizing daily life experience: the day reconstruction method. Science. 2004;306(5702):1776-1780.

26. Shiffman S, Stone AA, Hufford MR. Ecological momentary assessment. Annu Rev Clin Psychol. 2008;4:1-32.

27. Kim J, Nakamura T, Kikuchi H, Sasaki T, Yamamoto Y. Co-variation of depressive mood and locomotor dynamics evaluated by ecological momentary assessment in healthy humans. PLoS One. 2013;8(9):e74979.

28. Dockray S, Grant N, Stone AA, Kahneman D, Wardle J, Steptoe A. A comparison of affect ratings obtained with ecological momentary assessment and the day reconstruction method. Soc Indic Res. 2010;99(2):269-283.

29. Cohen S, Lemay EP. Why would social networks be linked to affect and health practices? Health Psychol. 2007;26(4):410-417.

30. Kamarck TW, Muldoon MF, Shiffman SS, Sutton-Tyrrell K. Experiences of demand and control during daily life are predictors of carotid atherosclerotic progression among healthy men. Health Psychol. 2007;26(3):324-332.

31. Kamarck TW, Shiffman SM, Smithline L, et al. The diary of ambulatory behavioral states: a new approach to the assessment of psychosocial influences on ambulatory cardiovascular activity. In: Krantz DS, Baum A, eds. Technology and Methods in Behavioral Medicine. Mahwah, NJ: Lawrence Erlbaum Associates; 1998:163-194.

32. Bass PF, Wilson JF, Griffith CH. A shortened instrument for literacy screening. J Gen Intern Med. 2003;18(12):1036-1038.

33. Weiss BD, Mays MZ, Martz W, et al. Quick assessment of literacy in primary care: the newest vital sign. Ann Fam Med. 2005;3(6):514-522.

34. Fagerlin A, Zikmund-Fisher BJ, Ubel PA, Jankovic A, Derry HA, Smith DM. Measuring numeracy without a math test: development of the Subjective Numeracy Scale. Med Decis Making. 2007;27(5):672-680.

35. Zikmund-Fisher BJ, Smith DM, Ubel PA, Fagerlin A. Validation of the subjective numeracy scale: effects of low numeracy on comprehension of risk communications and utility elicitations. Med Decis Making. 2007;27(5):663-671.

36. Liberali JM, Reyna VF, Furlan S, Stein LM, Pardo ST. Individual differences in numeracy and cognitive reflection, with implications for biases and fallacies in probability judgment. J Behav Decis Mak. 2012;25(4):361-381.

37. Blumberg SJ, Bialostosky K, Hamilton WL, Briefel RR. The effectiveness of a short form of the household food security scale. Am J Public Health. 1999;89(8):1231-1234.

38. Kroenke K, Spitzer RL, Williams JB. The Phq-9. J Gen Intern Med. 2001; 16(9):606-613.

39. Kroenke K, Strine TW, Spitzer RL, Williams JB, Berry JT, Mokdad AH. The PHQ-8 as a measure of current depression in the general population. J Affect Disord. 2009;114(1):163-173.

40. Kroenke K, Spitzer RL, Williams JB, Löwe B. The patient health questionnaire somatic, anxiety, and depressive symptom scales: a systematic review. Gen Hosp Psychiatry. 2010;32(4):345-359. 
41. Stunkard AJ, Sørensen T, Schulsinger F. Use of the Danish Adoption Register for the study of obesity and thinness. Res Publ Assoc Res Nerv Ment Dis. 1983; 60:115.

42. Shmueli E, Singh VK, Lepri B, Pentland A. Sensing, understanding, and shaping social behavior. IEEE Transactions on Computational Social Systems. 2014;1(1):22-34.

43. Bronner Y, Boyington JE. Developing weight loss interventions for AfricanAmerican women: elements of successful models. J Natl Med Assoc. 2002;94(4): 224-235.

44. Ard JD, Zunker C, Qu H, et al. Cultural perceptions of weight in African American and Caucasian women. Am J Health Behav. 2013;37(1):3-13.
45. Barnes AS, Goodrick GK, Pavlik V, Markesino J, Laws DY, Taylor WC. Weight loss maintenance in African-American women: focus group results and questionnaire development. J Gen Intern Med. 2007;22(7):915-922.

46. Hendley Y, Zhao L, Coverson DL, et al. Differences in weight perception among blacks and whites. J Womens Health (Larchmt). 2011;20(12):1805-1811.

47. Lucan SC, Barg FK, Long JA. Promoters and barriers to fruit, vegetable, and fast-food consumption among urban, low-income African Americans-a qualitative approach. Am J Public Health. 2010;100(4):631-635.

48. Samuel-Hodge CD, Gizlice Z, Cai J, Brantley PJ, Ard JD, Svetkey LP. Family functioning and weight loss in a sample of African Americans and whites. Ann Behav Med. 2010;40(3):294-301. 